Article

\title{
Compositional Variation in Sugars and Organic Acids at Different Maturity Stages in Selected Small Fruits from Pakistan
}

\author{
Tahir Mahmood ${ }^{1}$, Farooq Anwar ${ }^{1,2, *}$, Mateen Abbas ${ }^{3}$, Mary C. Boyce ${ }^{4}$ and Nazamid Saari ${ }^{5, *}$
}

1 Department of Chemistry and Biochemistry, University of Agriculture, Faisalabad-38040, Pakistan; E-Mail: ranatahiruaf@yahoo.com

2 Department of Chemistry, University of Sargodha, Sargodha-40100, Pakistan

3 Quality Operation Laboratory (QOL), University of Veterinary and Animal Sciences (UVAS), Lahore 54000, Pakistan; E-Mail: hafizmateen2002@yahoo.com

4 School of Natural Sciences, Edith Cowan University, Perth, Western Australia 6027, Australia; E-Mail: m.boyce@ecu.edu.au

5 Faculty of Food Science and Technology, Universiti Putra Malaysia, Serdang, Sclangor 43400, Malaysia

* Authors to whom correspondence should be addressed; E-Mails: fqanwar@yahoo.com (F.A.); nazamid@putra.upm.edu.my (N.S.); Tel.: +92-41-9200161-70 (F.A.); +6-038-946-838-5 (N.S.); Fax: +92-41-9200764 (F.A.); +6-038-942-355-2 (N.S.).

Received: 21 November 2011; in revised form: 4 January 2012 / Accepted: 9 January 2012 / Published: 27 January 2012

\begin{abstract}
Selected soluble sugars and organic acids were analyzed in strawberry, sweet cherry, and mulberry fruits at different ripening stages by HPLC. The amounts of fructose, glucose and sucrose were found to be: strawberry (1.79-2.86, 1.79-2.25 and $0.01-0.25 \mathrm{~g} / 100 \mathrm{~g} \mathrm{FW})$, sweet cherry $(0.76-2.35,0.22-3.39$ and $0.03-0.13 \mathrm{~g} / 100 \mathrm{~g})$ and mulberry (3.07-9.41, $1.53-4.95$ and $0.01-0.25 \mathrm{~g} / 100 \mathrm{~g}$ ) at un-ripened to fully-ripened stages, respectively. The strawberry, sweet cherry and mulberry mainly contained tartaric, citric and ascorbic acids in the range of 16-55, 70-1934 and 11-132 mg/100 g; 2-8, 2-10 and $10-17 \mathrm{mg} / 100 \mathrm{~g} ; 2-118,139-987$ and $2-305 \mathrm{mg} / 100 \mathrm{~g}$ at un-ripened to fully-ripened stages, respectively. Fructose and glucose were established to be the major sugars in all the tested fruit while citric and ascorbic acid were the predominant organic acids in strawberry and mulberry while tartaric acid was mainly present in sweet cherry. The tested fruits mostly showed an increase in the concentration of sugars and organic acids with ripening.
\end{abstract}

Keywords: berries; mulberry; sweet cherry; fruit composition; fruit maturity; HPLC 


\section{Introduction}

Fruits and vegetables are important sources of some essential dietary micronutrients. In particular, fruits are being increasingly recognized as a rich source of bioactive compounds including antioxidants, natural sugars and organic acids [1]. The popularity and acceptability of fruit among consumers is not only due to their high nutritive value, characteristic taste and flavor but also due to their known health promoting properties (as sources of bioactive compounds). Ripeness and maturity are the key factors that influence the taste of a fruit. Fruit ripening is a complex process influenced by several factors. The changes in composition of sugars and organic acids and volatile compounds during ripening process play a key role in flavor development and can affect the chemical and sensory characteristics (e.g., pH, total acidity, microbial stability, sweetness) of fruit [2]. For this reason, the assessment of sugars and organic acids content of a fruit is of interest to food experts and researchers.

The growing potential of berries and cherries fruits both as a food and cash crop has received much attention in Asia including Pakistan. The commercial importance of strawberry, cherry and mulberry fruits, as a nutritive and functional food commodity has stimulated the researchers to investigate the nutrients and chemicals composition of such fruits worldwide [3-6]. Research has shown that fruits, including strawberries and cherries, accumulate sugars such as glucose, fructose and sucrose and organic acids namely citric and malic acids [7-10]. However, there are some qualitative and quantitative variations reported in the composition of individual sugars and acids in relation to the cultivar, genotype and maturation stages thus affecting the overall nutritive quality and consumer's acceptability of the fruits [11-15]. Kafkas et al. [16] studied a number of strawberry genotypes and found that in most of the cases fructose was the predominant sugar and its content increased with ripening. By comparison, change in citric acid concentration with ripening varied with genotype while the concentration of malic acid in all the genotypes studied did not change during ripening. In another study on strawberries by Basson et al. [5], glucose was found to be the predominant sugar and consistent with the study by Kafkas et al. [16] its concentration increased with ripeness. Serrano et al. [12] reported an increase in the amounts of glucose and fructose as the sweet cherry fruit progressed from un-ripened to ripened phase. Serradilla et al. [10] reported that the fructose levels increased with ripening but the glucose levels decreased in sweet cherry cultivars.

Some studies on the variation of sugars and organic acids of small fruits such as strawberry, cherry and mulberry have been reported with regard to cultivars and fruit maturation, around the world [16-18]. As far as we know there have been no any reports to date compiled on the composition of individual sugars and organic acids at ripening stages of strawberry, sweet cherry and mulberry fruits of different cultivars grown in Pakistan. The purpose of this study was to examine the sugars (fructose, glucose and sucrose) and organic acids (malic, tartaric, citric and ascorbic acid) profiles of the selected fruits at un-ripened, semi-ripened and fully-ripened stages.

\section{Results and Discussion}

\subsection{Effect of Ripening on Total Soluble Solids and Titrable Acidity}

Significant increase for total soluble solids (TSS) and titrable acidity (TA) existed in the selected fruits in relation to maturity stages (Table 1$)$. TSS ( $\%{ }^{\circ}$ Brix) increased as the maturity progressed and 
Morus laevigata has the highest amount (15.62\%) in the tested fruits, similar increasing trend was also observed for TA (\%). According to Ercisli and Orhan [19], the levels of 15.9-20.4\% for TSS and $0.25-1.40 \%$ for TA investigated at fully-ripened stage in white mulberry genotypes are in close agreement to our present data. Similarly, Koyuncu et al. [20] reported 13.11 to $16.23 \%$ TSS and $1.35-1.86 \%$ TA in black mulberry genotype; these values are also comparable with present values. In agreement with the present study trends, Diaz-Mula et al. [21] also reported an increase in TSS and TA in different cultivars of cherry fruits analyzed from Spain as the maturity progressed. In a recent study by Chang and Chang [22], M. laevigata cultivar from Taiwan exhibited somewhat higher TSS (20.1\%) as compared with M. laevigata species from Pakistan. A higher value of TSS is related to greater sweetness and superior eating quality of a fruit [22].

Table 1. Total soluble solids $\left(\%{ }^{\circ}\right.$ Brix $)$ and titrable acidity ( $\%$ as citric acid equivalent $)$ of selected fruits at different maturity stages

\begin{tabular}{|c|c|c|c|c|c|c|c|c|}
\hline & \multirow{2}{*}{$\begin{array}{l}\text { Fruit } \\
\text { Stage }\end{array}$} & \multicolumn{2}{|c|}{ Strawberry } & \multirow{2}{*}{ Sweet Cherry } & \multicolumn{2}{|c|}{ Long Mulberry } & \multicolumn{2}{|c|}{ Small Mulberry } \\
\hline & & Korona & Tufts & & M. laevigata & M. macroura & M. nigra & M. alba \\
\hline TSS & UN & $5.12 \pm 0.6^{\mathrm{c}}$ & $4.31 \pm 0.6^{\mathrm{c}}$ & $7.13 \pm 0.4^{c}$ & $8.21 \pm 0.3^{c}$ & $7.44 \pm 0.3^{c}$ & $6.90 \pm 0.6^{\mathrm{c}}$ & $5.66 \pm 0.2^{c}$ \\
\hline \multirow[t]{2}{*}{$\left({ }^{\circ} \mathrm{Brix}\right)$} & SR & $8.76 \pm 1.1^{b}$ & $7.34 \pm 0.3^{b}$ & $9.62 \pm 0.4^{b}$ & $12.5 \pm 0.8^{b}$ & $11.98 \pm 0.5^{b}$ & $9.26 \pm 0.7^{b}$ & $8.35 \pm 0.4^{b}$ \\
\hline & FR & $10.11 \pm 0.9^{\mathrm{a}}$ & $9.45 \pm 0.6^{\mathrm{a}}$ & $14.17 \pm 0.6^{\mathrm{a}}$ & $15.62 \pm 1.2^{\mathrm{a}}$ & $12.49 \pm 0.9^{\mathrm{a}}$ & $12.67 \pm 1.1^{\mathrm{a}}$ & $10.12 \pm 0.5^{\mathrm{a}}$ \\
\hline TA & UN & $0.21 \pm 0.1^{\mathrm{c}}$ & $0.31 \pm 0.1^{\mathrm{c}}$ & $0.23 \pm 0.1^{\mathrm{c}}$ & $0.31 \pm 0.2^{\mathrm{c}}$ & $0.20 \pm 0.1^{\mathrm{c}}$ & $0.65 \pm 0.3^{\mathrm{c}}$ & $0.21 \pm 0.1^{\mathrm{c}}$ \\
\hline \multirow[t]{2}{*}{$(\%)$} & SR & $0.56 \pm 0.2^{b}$ & $0.45 \pm 0.2^{b}$ & $0.43 \pm 0.2^{b}$ & $1.12 \pm 0.5^{b}$ & $0.76 \pm 0.5^{b}$ & $1.15 \pm 0.6^{b}$ & $0.46 \pm 0.3^{b}$ \\
\hline & FR & $0.79 \pm 0.4^{\mathrm{a}}$ & $0.99 \pm 0.4^{\mathrm{a}}$ & $0.85 \pm 0.3^{\mathrm{a}}$ & $1.74 \pm 0.4^{\mathrm{a}}$ & $1.28 \pm 0.5^{\mathrm{a}}$ & $1.28 \pm 0.1^{\mathrm{a}}$ & $1.01 \pm 0.5^{\mathrm{a}}$ \\
\hline
\end{tabular}

Values (mean $\pm \mathrm{SD}$ ) are average of three samples of each fruit, analyzed individually in triplicate $(p<0.05)$. Different superscript letters with in the same column represent significant differences among ripening stages per TSS ( $\left.\%{ }^{\circ} \mathrm{Brix}\right)$ and $\mathrm{TA}(\%) . \mathrm{UN}=$ un-ripened $\mathrm{SR}=$ semi-ripened $\mathrm{FR}=$ fully-ripened.

\subsection{Sensory Analysis}

The effects of maturity on some sensory attributes such as texture, flavor and appearance of fruits are presented in Table 2. As fruit progressed from un-ripened to full-ripened stage, significant $(p<0.05)$ improvement in flavor, appearance and texture were recorded by the panelist. Taking into account data for flavor, appearance, texture, acidity and TSS (sensory and nutritive parameters), the fruits more appreciated could be "M. laevigata", "korona" and M. macroura. From commercial view-point, in strawberry, mulberry and sweet cherry, appearance is considered to be an important quality index that has the strongest influence over price formation. Chitarra and Chitarra [23] reported a positive and significant correlation between TSS and flavor. Flavor of a fruit is characterized by several factors such as sweetness, acidity, and astringency, in combination with aroma, due to the volatile compounds involved. Generally higher values of TA in a typical fruit are negatively linked with the flavor and consumer acceptance [23]. 
Table 2. Sensory evaluation (mean acceptance score, $1=$ dislike extremely $5=$ neither like nor dislike $9=$ like extremely) based on flavor, appearance and texture of selected fruits at different maturity stages

\begin{tabular}{|c|c|c|c|c|c|c|c|c|}
\hline & \multirow{2}{*}{$\begin{array}{l}\text { Fruit } \\
\text { Stage }\end{array}$} & \multicolumn{2}{|c|}{ Strawberry } & \multirow{2}{*}{ Sweet Cherry } & \multicolumn{2}{|c|}{ Long Mulberry } & \multicolumn{2}{|c|}{ Small Mulberry } \\
\hline & & Korona & Tufts & & M. laevigata & M. macroura & M. nigra & M. alba \\
\hline \multirow{3}{*}{$\begin{array}{c}\text { Flavor } \\
(1-9 \text { scale })\end{array}$} & UN & $2.3^{c}$ & $2.6^{\mathrm{c}}$ & $3.1^{\mathrm{c}}$ & $2.4^{\mathrm{c}}$ & $1.9^{\mathrm{c}}$ & $2.4^{\mathrm{c}}$ & $2.2^{c}$ \\
\hline & SR & $4.6^{\mathrm{b}}$ & $4.8^{b}$ & $5.7^{b}$ & $5.0^{\mathrm{b}}$ & $6.2^{b}$ & $4.7^{b}$ & $4.1^{\mathrm{b}}$ \\
\hline & FR & $7.6^{\mathrm{a}}$ & $6.9^{\mathrm{a}}$ & $8.2^{\mathrm{a}}$ & $8.1^{\mathrm{a}}$ & $9.0^{\mathrm{a}}$ & $7.8^{\mathrm{a}}$ & $8.3^{\mathrm{a}}$ \\
\hline \multirow{3}{*}{$\begin{array}{l}\text { Appearance } \\
\text { (1-9 scale) }\end{array}$} & UN & $3.2^{\mathrm{c}}$ & $2.8^{\mathrm{c}}$ & $3.6^{\mathrm{c}}$ & $3.8^{c}$ & $1.7^{\mathrm{c}}$ & $2.5^{c}$ & $2.1^{\mathrm{c}}$ \\
\hline & SR & $5.8^{b}$ & $5.4^{\mathrm{b}}$ & $6.6^{b}$ & $6.4^{\mathrm{b}}$ & $2.5^{b}$ & $6.1^{\mathrm{b}}$ & $4.3^{b}$ \\
\hline & FR & $8.3^{\mathrm{a}}$ & $7.9^{\mathrm{a}}$ & $8.2^{\mathrm{a}}$ & $7.9^{\mathrm{a}}$ & $6.7^{\mathrm{a}}$ & $8.3^{\mathrm{a}}$ & $6.7^{\mathrm{a}}$ \\
\hline \multirow{3}{*}{$\begin{array}{c}\text { Texture } \\
(1-9 \text { scale })\end{array}$} & UN & $3.1^{\mathrm{c}}$ & $1.9^{c}$ & $1.2^{\mathrm{c}}$ & $1.3^{c}$ & $1.5^{\mathrm{c}}$ & $1.6^{\mathrm{c}}$ & $1.5^{\mathrm{c}}$ \\
\hline & SR & $5.8^{b}$ & $4.3^{b}$ & $5.1^{b}$ & $5.3^{b}$ & $3.4^{\mathrm{b}}$ & $4.7^{b}$ & $4.1^{b}$ \\
\hline & FR & $8.6^{\mathrm{a}}$ & $8.1^{\mathrm{a}}$ & $7.2^{\mathrm{a}}$ & $7.5^{\mathrm{a}}$ & $7.2^{\mathrm{a}}$ & $8.1^{\mathrm{a}}$ & $6.3^{\mathrm{a}}$ \\
\hline
\end{tabular}

Values are average of three samples of each fruit, analyzed individually in triplicate $(p<0.05)$. Different superscript letters with in the same column represent significant difference among ripening stages. $\mathrm{UN}=$ un-ripened $\mathrm{SR}=$ semi-ripened $\mathrm{FR}=$ fully-ripened.

\subsection{Effect of Ripening on Sugars Content}

Statistically significant $(p<0.05)$ variations in the amounts of three key sugars namely fructose, glucose and sucrose were found in strawberry, sweet cherry and mulberry fruits with regard to the three maturity stages (Table 3).

The total sugar contents (sum of sucrose, glucose and fructose) for ripe strawberries in the present study ranged from 4.8-5.4 g/100 g FW. These levels fell in the range of those investigated earlier, wherein the total sugar concentrations of $8.2 \mathrm{~g} / 100 \mathrm{~g} \mathrm{FW}$ [24] and $3.6 \mathrm{~g} / 100 \mathrm{~g} \mathrm{FW}$ [5] were reported. In the present study glucose and fructose were the predominant sugars for each of the strawberry varieties studied, while sucrose was usually present at lower concentrations, typically 5-10 times lower. Literature studies indicate that there is some variation, and little consistency with respect to the relative concentrations of the sugars. Basson et al. [5] reported that glucose (1.6-1.8 g/100 g FW) was the predominant sugar in ripe strawberry fruit of two cultivars Festival and Ventana while the sucrose (0.9-1.1 g/100 g FW) and fructose (0.9-1.2 g/100 g FW), with almost similar concentration, were lower relative to glucose. Castro et al. [24] studied the concentration of the sugars in ripe strawberries from the cultivars Camaraso and Selva and found that, in agreement with this study, fructose and glucose were the main sugars, 3.1-5.5 and 3.5-6.7 g/100 g FW, respectively and that of sucrose (0.6-0.9 g/100 g FW) was present at relatively lower level. Similarly, Sturm et al. [25] studied 13 strawberry varieties and reported sucrose and glucose to be the dominant sugars, the content of the former component were typically 10 times lower than the later.

In sweet cherry, fructose $(2.34 \mathrm{~g} / 100 \mathrm{~g} \mathrm{FW})$ was the predominant sugar followed by glucose $(0.39 \mathrm{~g} / 100 \mathrm{~g} \mathrm{FW})$ and sucrose $(0.13 \mathrm{~g} / 100 \mathrm{~g} \mathrm{FW})$. In agreement to the present study trend, Serradilla et al. [10] also reported an increase in the fructose level during ripening of sweet cherry. The total sugar content for ripe sweet cherry, $2.87 \mathrm{~g} / 100 \mathrm{~g} \mathrm{FW}$, in the present study was lower than that reported by Serrano et al. [12]. 
Table 3. Sugars composition (g/100 g on FW) of selected fruits at different ripening stages

\begin{tabular}{|c|c|c|c|c|c|c|c|c|}
\hline \multirow{2}{*}{ Sugars } & \multirow{2}{*}{ Fruit Stage } & \multicolumn{2}{|c|}{ Strawberry } & \multirow{2}{*}{ Sweet Cherry } & \multicolumn{2}{|c|}{ Long Mulberry } & \multicolumn{2}{|c|}{ Small Mulberry } \\
\hline & & Korona & Tufts & & M. laevigata & M. macroura & M. nigra & M. alba \\
\hline \multirow{3}{*}{ Fructose } & Un-ripened & $2.55 \pm 0.26^{\mathrm{a}}$ & $1.79 \pm 0.10^{b}$ & $0.76 \pm 0.01^{\mathrm{c}}$ & $3.07 \pm 0.21^{\mathrm{a}}$ & $5.72 \pm 0.68^{c}$ & $3.81 \pm 0.23^{\mathrm{c}}$ & $3.24 \pm 0.21^{\mathrm{c}}$ \\
\hline & Semi-ripened & $2.78 \pm 0.17^{\mathrm{a}}$ & $2.39 \pm 0.12^{\mathrm{a}}$ & $1.64 \pm 0.14^{\mathrm{b}}$ & $3.50 \pm 0.21^{b}$ & $6.93 \pm 0.57^{\mathrm{b}}$ & $4.15 \pm 0.27^{b}$ & $3.90 \pm 0.11^{b}$ \\
\hline & Fully-ripened & $2.86 \pm 0.15^{\mathrm{a}}$ & $2.52 \pm 0.22^{\mathrm{a}}$ & $2.35 \pm 0.17^{\mathrm{a}}$ & $4.59 \pm 0.18^{\mathrm{a}}$ & $9.41 \pm 0.54^{\mathrm{a}}$ & $5.36 \pm 0.19^{\mathrm{a}}$ & $4.97 \pm 0.12^{\mathrm{a}}$ \\
\hline \multirow{3}{*}{ Glucose } & Un-ripened & $1.89 \pm 0.24^{b}$ & $1.79 \pm 0.21^{b}$ & $0.22 \pm 0.00^{b}$ & $1.53 \pm 0.18^{b}$ & $3.83 \pm 0.16^{b}$ & $1.84 \pm 0.08^{b}$ & $2.44 \pm 0.20^{b}$ \\
\hline & Semi-ripened & $2.15 \pm 0.20^{\mathrm{a}}$ & $2.25 \pm 0.12^{\mathrm{a}}$ & $0.27 \pm 0.01^{b}$ & $0.93 \pm 0.09^{\mathrm{c}}$ & $4.35 \pm 0.18^{b}$ & $1.86 \pm 0.08^{b}$ & $2.90 \pm 0.10^{b}$ \\
\hline & Fully-ripened & $2.25 \pm 0.21^{\mathrm{a}}$ & $2.12 \pm 0.14^{\mathrm{a}}$ & $0.39 \pm 0.01^{\mathrm{a}}$ & $3.39 \pm 0.22^{\mathrm{a}}$ & $4.95 \pm 0.24^{\mathrm{a}}$ & $2.50 \pm 0.15^{\mathrm{a}}$ & $3.21 \pm 0.12^{\mathrm{a}}$ \\
\hline \multirow{3}{*}{ Sucrose } & Un-ripened & $0.01 \pm 0.00^{b}$ & $0.03 \pm 0.00^{b}$ & $0.03 \pm 0.00^{\mathrm{b}}$ & $0.19 \pm 0.03^{\mathrm{a}}$ & $0.19 \pm 0.02^{\mathrm{a}}$ & $0.25 \pm 0.04^{\mathrm{a}}$ & $0.04 \pm 0.00^{\mathrm{a}}$ \\
\hline & Semi-ripened & $0.02 \pm 0.00^{b}$ & $0.06 \pm 0.00^{b}$ & $0.10 \pm 0.00^{\mathrm{a}}$ & $0.03 \pm 0.00^{b}$ & $0.02 \pm 0.00^{b}$ & $0.04 \pm 0.01^{b}$ & $0.02 \pm 0.00^{b}$ \\
\hline & Fully-ripened & $0.25 \pm 0.01^{\mathrm{a}}$ & $0.20 \pm 0.01^{\mathrm{a}}$ & $0.13 \pm 0.01^{\mathrm{a}}$ & $0.01 \pm 0.00^{\mathrm{b}}$ & $0.01 \pm 0.00^{\mathrm{b}}$ & $0.07 \pm 0.00^{\mathrm{b}}$ & $0.01 \pm 0.00^{\mathrm{b}}$ \\
\hline \multirow{3}{*}{ Total Sugars } & Un-ripened & $4.45 \pm 0.42^{a}$ & $3.61 \pm 0.18^{b}$ & $1.01 \pm 0.01^{\mathrm{b}}$ & $4.80 \pm 0.21^{b}$ & $9.75 \pm 0.32^{c}$ & $5.90 \pm 0.18^{b}$ & $5.72 \pm 0.31^{b}$ \\
\hline & Semi-ripened & $4.95 \pm 0.35^{\mathrm{a}}$ & $4.70 \pm 0.33^{\mathrm{a}}$ & $2.01 \pm 0.11^{\mathrm{a}}$ & $4.46 \pm 0.21^{\mathrm{b}}$ & $11.30 \pm 0.51^{\mathrm{b}}$ & $6.05 \pm 0.27^{b}$ & $6.82 \pm 0.16^{b}$ \\
\hline & Fully-ripened & $5.36 \pm 0.47^{\mathrm{a}}$ & $4.84 \pm 0.21^{\mathrm{a}}$ & $2.87 \pm 0.15^{\mathrm{a}}$ & $8.00 \pm 0.49^{\mathrm{a}}$ & $14.39 \pm 0.71^{\mathrm{a}}$ & $7.93 \pm 0.23^{\mathrm{a}}$ & $8.19 \pm 0.64^{\mathrm{a}}$ \\
\hline \multirow{3}{*}{$\begin{array}{c}\text { Sweetness } \\
\text { (Suceq) }\end{array}$} & Un-ripened & $5.82^{b}$ & $4.45^{b}$ & $1.51^{\mathrm{c}}$ & $6.63^{b}$ & $12.92^{\mathrm{c}}$ & $8.20^{\mathrm{b}}$ & $7.45^{c}$ \\
\hline & Semi-ripened & $6.38^{\mathrm{a}}$ & $5.86^{\mathrm{a}}$ & $3.14^{\mathrm{b}}$ & $6.77^{\mathrm{b}}$ & $15.23^{b}$ & $8.60^{\mathrm{b}}$ & $8.91^{\mathrm{b}}$ \\
\hline & Fully-ripened & $6.86^{\mathrm{a}}$ & $6.13^{\mathrm{a}}$ & $4.48^{\mathrm{a}}$ & $10.46^{\mathrm{a}}$ & $19.95^{\mathrm{a}}$ & $11.19^{\mathrm{a}}$ & $10.98^{\mathrm{a}}$ \\
\hline
\end{tabular}

Values (mean \pm SD) are average of three samples of each fruit, analyzed individually in triplicate $(p<0.05)$. Different superscript letters with in the same column represent significant difference among ripening stages per individual sugar. 
Within the mulberry fruits, fructose was determined to be the principle sugar compound. Morus laevigata, M. macroura, the long mulberry fruits, contained 3.07 and $5.72 \mathrm{~g} / 100 \mathrm{~g}$ fructose at un-ripened stage and 4.59 and $9.41 \mathrm{~g} / 100 \mathrm{~g}$ at fully-ripened stage, respectively showing an increasing trend in the content of this sugar as maturity progressed from un-ripened to fully-ripened stage. The glucose content of these two mulberry fruits also increased with ripeness; however a reverse trend was observed for sucrose, the concentration of which decreased with ripening. Similar results were also recorded for small mulberry namely $M$. nigra and $M$. alba fruits investigated as part of this study (Table 3). Ozgen et al. [18] reported that M. nigra and $M$. rubra contained fructose in the range of 4.86-6.41 and 2.77-4.66 g/100 mL, glucose (5.50-7.12, 2.85-4.96 g/100 mL) and sucrose (0.01-0.07, $0.04-0.10 \mathrm{~g} / 100 \mathrm{~mL}$ ), respectively. Nevertheless, there are no detailed data on the sugars composition of Morus laevigata and M. macroura with which we can compare our present results.

The total contents of sugars among mulberry fruits at fully-ripened stage varied between $7.93 \mathrm{~g} / 100 \mathrm{~g}$ (M. laevigata) to $14.39 \mathrm{~g} / 100 \mathrm{~g} \mathrm{FW}$ (M. macroura). These values are in line to those investigated earlier by Ahmad and Sadozai [26] for ripe black mulberry fruit (9\%) from another province namely Khyber Pakhtunkhwa, Pakistan. In consistent with our present data, Elmac and Altuq [27] reported the total sugar contents to be varied between 11.3 and $16.2 \%$ in three black mulberry (M. nigra) cultivars from Aegean region of Turkey. The slight variations in the total sugar contents of different mulberry fruits may be due to differences in genotypes and agroclimatic conditions of the harvesting regions.

Overall, the contents of total sugars varied widely among the different fruits analyzed, the highest amount was determined in fully-ripened M. macroura $(14.39 \mathrm{~g} / 100 \mathrm{~g})$ while the lowest in fully ripened sweet cherry $(2.87 \mathrm{~g} / 100 \mathrm{~g})$ fruits. This can be supported by the literature which reveals that soluble sugar composition in fruits varies among species, varieties, and cultivars [28]. As far as is concerned about the effect of fruit maturation/ripening on the individual sugars, the concentration of glucose and fructose generally increased as the maturity progressed from unripe to ripened stage for all the tested fruits. The content of sucrose increased in strawberry and sweet cherry; while its concentration decreased regularly in mulberry cultivars as the maturity progressed. In agreement with the present investigation, some previous reports also reveal that the content of sugars (fructose, glucose and sucrose) varies with fruit maturity depending upon the cultivation regimes and harvest time [10,24,29].

A total sweetness index concept was used to assess fruit sweetness as sucrose equivalent (Suceq) (Table 3). Based on these results, M. macroura had the highest total sweetness index (19.95 Suceq) followed by M. nigra (11.19 Suceq) while sweet cherry had the lowest sweetness index (4.48 Suceq) at fully ripened stage. The sweetness index reported by Crespo et al. [6] in four strawberry cultivars (viz., Antea, Asia, Clery, Matis), ranging from 5.31-8.32, was within the range of this study values.

\subsection{Effect of Ripening on Organic Acids Composition}

Statistically significant $(p<0.05)$ differences were found for malic, citric, ascorbic, and total acid contents of the fruits studied at different maturity stages (Table 4). For the strawberry varieties studied, citric acid (1200-1434 mg/100 g FW) was the dominant organic acid at the fully-ripened stage and was typically present at concentrations 10 times higher than the second most abundant acid, ascorbic acid (90-131 mg/100 g FW). Tartaric acid was detected at concentration 48-55 mg/100 g FW, while 
malic acid was present at much lower concentrations $(0.7-2.6 \mathrm{mg} / 100 \mathrm{~g} \mathrm{FW})$. The presently determined concentration of tartaric acid in strawberry is quite comparable with that investigated by Koyunch and Dilmacunal [30] in "Dorit" (40 mg/100 g) and "Selva" (48 mg/100 g) cultivars of strawberry. Tartaric acid, which can not only inhibit the precipitation of melanin, but can, also moisten the skin, is useful against dry skin. Fruits rich in tartaric acid such as star fruit are undoubtedly good for maintain healthy skin. As the strawberry cultivars studied presently from Pakistan, do contain considerable amount of tartaric acid, these can be explored as a valuable moistening agent for cosmetics products.

In agreement with our present results, Holcroft et al. [31] also found citric acid as the principle organic acid in strawberry. Similarly, the study conducted by Castro et al. [24] on fresh Camarosa and Selva strawberry cultivars at fully ripening stage also reported citric acid $(747 \mathrm{mg} / 100 \mathrm{~g})$ to be the most abundant organic acid and malic acid $(117,20 \mathrm{mg} / 100 \mathrm{~g})$ to be the least abundant of the acids studied, however, the concentration of malic acid was relatively higher compared to the present study. Organic acids content of strawberry fruit increased as the fruit maturity progressed; the most significant increase in the content of ascorbic acid was observed. Other authors have also reported marked increase in the ascorbic acid content of strawberries fruit during ripening [7,32,33].

Meanwhile, ascorbic acid was determined as the major organic acid (17 mg/100 g) in fully ripened sweet cherry fruit followed by citric acid, tartaric acid and malic acid. Usenik et al. [15], in contrast to present finding, determined malic acid with contribution $353-812 \mathrm{mg} / 100 \mathrm{~g} \mathrm{FW}$, as the principle organic acid among different cultivars of sweet cherry. Likewise, in another study by Souci et al. [34], malic acid was found to be the major acid in fully ripened cherry fruit.

For the mulberry species studied, citric acid (773-987 mg/100 g FW) was the most abundant organic acid found in M. laevigata and M. nigra at fully-ripened stage, however it was not detected in other Morus species. Ascorbic acid (17-305 mg/100 g FW) was the second main acid, determined to be 10 times higher in M. macroura and M. nigra than in M. laevigata and M. alba. Tartaric was also present in considerable amounts $(10-118 \mathrm{mg} / 100 \mathrm{~g} \mathrm{FW})$ while malic acid was present at a smaller concentrations (2.6-4.1 mg/100 g FW). In contradictory to our present result, black mulberry genotype, grown in different agro climatic regions of Turkey, contained malic acid, in the range of $123-209 \mathrm{mg} / \mathrm{g}$, as the major acid followed by citric acid $(21-41 \mathrm{mg} / \mathrm{g}$ ) [19]. Similarly, in another investigation, malic acid was determined to be the predominant acid with an average amount of $57.5 \mathrm{mg} / \mathrm{g}$, while citric $8.2 \mathrm{mg} / \mathrm{g}$ and tartaric $3.4 \mathrm{mg} / \mathrm{g}$ were the other important acids found in M. nigra, black mulberry from Sutculer districts of Isparta, Turkey [20]. Nevertheless, there are no literature data on the organic acids analysis of Morus laevigata, M. macroura with which to compare the values of this study. Ozgen et al. [18] conducted a study on $M$. nigra accessions; citric acid was $92 \%$ of the total acids while malic acid was only $8 \%$. The same ratios were 15 and $85 \%$, respectively, for M. laevigata.

Overall, among the fruits tested, strawberry cultivars were found to be the main source of total organic acids contents (1300-1600 mg/100 g FW). As far as is concerned about the distribution of individual organic acids, ascorbic was found to be principle component in sweet cherry, $M$. nigra and $M$. macroura while citric acid in strawberry cultivars, M. laevigata and M. nigra imparting these species a superior nutritional value. Overall, during fruit development, the amount of selected organic acids increased in strawberry, sweet cherry and mulberry as maturity progressed. 
Table 4. Organic acids content $(\mathrm{mg} / 100 \mathrm{~g}$ on $\mathrm{FW})$ in selected fruits at different ripening stages

\begin{tabular}{|c|c|c|c|c|c|c|c|c|}
\hline \multirow{2}{*}{ Organic Acids } & \multirow{2}{*}{ Stages } & \multicolumn{2}{|c|}{ Strawberry } & \multirow{2}{*}{ Sweet Cherry } & \multicolumn{2}{|c|}{ Long Mulberry } & \multicolumn{2}{|c|}{ Small Mulberry } \\
\hline & & Korona & Tufts & & M. laevigata & M. macroura & M. nigra & M. alba \\
\hline \multirow{3}{*}{ Malic acid } & Un-ripened & $0.5 \pm 0.0^{\mathrm{a}}$ & $0.3 \pm 0.0^{\mathrm{a}}$ & $0.2 \pm 0.0^{\mathrm{a}}$ & $1.2 \pm 0.2^{\mathrm{a}}$ & Traces $^{A}$ & $0.4 \pm 0.0^{\mathrm{a}}$ & Traces $^{\mathrm{A}}$ \\
\hline & Semi-ripened & $0.5 \pm 0.0^{\mathrm{b}}$ & $0.9 \pm 0.0^{b}$ & $1.6 \pm 0.1^{\mathrm{b}}$ & $1.9 \pm 0.0^{\mathrm{a}}$ & Traces ${ }^{\mathrm{A}}$ & $0.5 \pm 0.0^{\mathrm{b}}$ & $2.3 \pm 0.2^{\mathrm{a}}$ \\
\hline & Fully-ripened & $0.7 \pm 0.0^{\mathrm{c}}$ & $2.6 \pm 0.1^{\mathrm{c}}$ & $2.3 \pm 0.0^{\mathrm{c}}$ & $2.6 \pm 0.1^{\mathrm{b}}$ & $0.5 \pm 0.0^{\mathrm{a}}$ & $2.1 \pm 0.0^{\mathrm{c}}$ & $4.1 \pm 1.2^{b}$ \\
\hline \multirow{3}{*}{ Tartaric acid } & Un-ripened & $41.0 \pm 0.7^{\mathrm{a}}$ & $16.1 \pm 0.4^{\mathrm{a}}$ & $2.3 \pm 0.3^{\mathrm{a}}$ & $2.4 \pm 0.1^{\mathrm{a}}$ & $13.0 \pm 2.0^{\mathrm{a}}$ & $9.9 \pm 0.2^{a}$ & $3.4 \pm 0.1^{\mathrm{a}}$ \\
\hline & Semi-ripened & $45.9 \pm 0.5^{b}$ & $38.7 \pm 0.7^{b}$ & $5.9 \pm 0.5^{b}$ & $6.6 \pm 1.7^{b}$ & $51.2 \pm 2.3^{b}$ & $46.4 \pm 0.4^{b}$ & $9.6 \pm 1.7^{b}$ \\
\hline & Fully-ripened & $48.8 \pm 0.8^{\mathrm{c}}$ & $55.6 \pm 0.6^{\mathrm{c}}$ & $8.3 \pm 0.7^{\mathrm{c}}$ & $10.1 \pm 0.9^{c}$ & $118.7 \pm 2.6^{\mathrm{c}}$ & $99.9 \pm 0.8^{\mathrm{c}}$ & $14.1 \pm 0.9^{\mathrm{c}}$ \\
\hline \multirow{3}{*}{ Citric acid } & Un-ripened & $70.1 \pm 2.3^{\mathrm{a}}$ & $95.6 \pm 2.9^{\mathrm{a}}$ & $2.3 \pm 0.1^{\mathrm{a}}$ & $234.2 \pm 8.1^{\mathrm{a}}$ & $\mathrm{nd}^{\mathrm{B}}$ & $139.0 \pm 1.9^{\mathrm{a}}$ & $\mathrm{nd}^{\mathrm{B}}$ \\
\hline & Semi-ripened & $172.1 \pm 1.4^{b}$ & $248.4 \pm 1.9^{b}$ & $5.4 \pm 0.2^{b}$ & $456.5 \pm 10.6^{b}$ & $\mathrm{nd}^{\mathrm{B}}$ & $256.3 \pm 2.6^{b}$ & $\mathrm{nd}^{\mathrm{B}}$ \\
\hline & Fully-ripened & $1202.4 \pm 5.8^{c}$ & $1434.3 \pm 3.8^{c}$ & $10.4 \pm 0.1^{\mathrm{c}}$ & $987.7 \pm 12.3^{c}$ & $\mathrm{nd}^{\mathrm{B}}$ & $773.8 \pm 4.0^{\mathrm{c}}$ & $\mathrm{nd}^{\mathrm{B}}$ \\
\hline \multirow{3}{*}{ Ascorbic acid } & Un-ripened & $10.9 \pm 0.9^{\mathrm{a}}$ & $18.8 \pm 0.6^{\mathrm{a}}$ & $9.6 \pm 0.6^{\mathrm{a}}$ & $6.3 \pm 0.2^{\mathrm{a}}$ & $23.1 \pm 2.3^{\mathrm{a}}$ & $11.6 \pm 0.9^{\mathrm{a}}$ & $2.3 \pm 0.9^{\mathrm{a}}$ \\
\hline & Semi-ripened & $45.8 \pm 0.4^{b}$ & $94.4 \pm 1.8^{b}$ & $13.2 \pm 1.9^{b}$ & $10.3 \pm 1.1^{b}$ & $65.3 \pm 4.6^{b}$ & $16.4 \pm 0.5^{b}$ & $16.4 \pm 2.4^{b}$ \\
\hline & Fully-ripened & $90.9 \pm 1.9^{\mathrm{c}}$ & $131.9 \pm 2.1^{\mathrm{c}}$ & $17.0 \pm 2.0^{\mathrm{c}}$ & $17.2 \pm 1.1^{\mathrm{c}}$ & $209.8 \pm 12.2^{\mathrm{c}}$ & $305.4 \pm 1.4^{\mathrm{c}}$ & $32.2 \pm 3.5^{\mathrm{c}}$ \\
\hline \multirow{3}{*}{ Total acid } & Un-ripened & $122.5 \pm 4.5^{c}$ & $130.8 \pm 3.7^{c}$ & $14.4 \pm 2.4^{\mathrm{c}}$ & $244.1 \pm 6.1^{\mathrm{c}}$ & $36.1 \pm 2.1^{\mathrm{c}}$ & $160.9 \pm 2.4^{c}$ & $5.7 \pm 0.2^{c}$ \\
\hline & Semi-ripened & $264.3 \pm 6.4^{\mathrm{b}}$ & $382.4 \pm 5.7^{b}$ & $26.1 \pm 3.2^{b}$ & $475.3 \pm 5.2^{b}$ & $116.5 \pm 3.2^{b}$ & $319.6 \pm 4.2^{b}$ & $28.3 \pm 3.2^{b}$ \\
\hline & Fully-ripened & $1342.8 \pm 16.9^{\mathrm{a}}$ & $1624.4 \pm 12.4^{\mathrm{a}}$ & $38.0 \pm 5.6^{\mathrm{a}}$ & $1017.6 \pm 9.8^{a}$ & $329.0 \pm 4.7^{\mathrm{a}}$ & $1181.2 \pm 8.4^{\mathrm{a}}$ & $50.4 \pm 4.1^{\mathrm{a}}$ \\
\hline
\end{tabular}

Values (mean \pm SD) are average of three samples of each fruit, analyzed individually in triplicate $(p<0.05)$. Different superscript letters with in the same column represent significant difference among ripening stages per individual organic acid. ${ }^{\mathbf{A}}$ Traces $=<0.04 ;{ }^{\mathbf{B}}$ nd $=$ not detected. 


\section{Experimental}

\subsection{Collection of Sample}

Fruit samples of strawberry (Fragaria x ananassa Duch), cultivars (Korona and tufts), sweet cherry (Prunus avium L.) and mulberry species (Morus alba, M. nigra, M. macroura and M. laevigata) at un-ripened, semi-ripened and fully-ripened stage were collected from the orchards in the region of Lahore, Kalat and Faisalabad, respectively of Pakistan during April-July, 2009. The selection of the fruits at different maturity stages was based upon their colour and texture (Table 5). The fruit ( $2 \mathrm{~kg}$ for each category) were collected in polyethylene bags, transferred to the experimental lab and stored in a refrigerator at $5{ }^{\circ} \mathrm{C}$ overnight for further analyses.

Table 5. Color/texture of selected fruits at different maturity stages

\begin{tabular}{ccccc}
\hline Fruits & Cultivar/Species & Un-ripened & Semi-ripened & Fully-ripened \\
\hline \multirow{2}{*}{ Strawberry } & Korona & Green/hard & Reddish green/semi-soft & Red/soft \\
& Tufts & Green/hard & Reddish green/semi-soft & Red/soft \\
Cherry & Sweet cherry & Green/hard & Red/semi-soft & Violet/soft \\
Long & M. laevigata & Light Green/hard & Red/semi-soft & Black/soft \\
mulberry & M. macroura & Light Green/hard & Light yellow/semi-soft & Off-white/soft \\
Small & M. nigra & Light Green/hard & Red/semi-soft & Black/soft \\
mulberry & M. alba & Light Green/hard & Light yellow/semi-soft & Off-white/soft \\
\hline
\end{tabular}

\subsection{Total Soluble Solids and Total Acidity}

Total soluble solids (TSS) were determined in the juice produced from fruits at each maturity stage using a digital refractometer Atago RX-7000cx (Atago Co. Ltd., Japan) at $25^{\circ} \mathrm{C}$ and results expressed as $\%{ }^{\circ}$ Brix. Total acidity (TA) of the juice ( $1 \mathrm{~mL}$ of diluted juice in $25 \mathrm{~mL}$ distilled $\left.\mathrm{H}_{2} \mathrm{O}\right)$ was determined by potentiometric titration against $0.1 \mathrm{~N} \mathrm{NaOH}$ up to $\mathrm{pH}$ 8.1. All determinations were made in triplicate and the results expressed as $\mathrm{g}$ of citric acid equivalent per $100 \mathrm{~g}$ fresh weight.

\subsection{Sensory Evaluation}

Sensory analysis was carried out by a 15 member panel consisting of University students and staff who were trained in a one-hour training session to become familiar with the characteristics of the fruits. Panel evaluated the fruit samples using sorting-preference tests and hedonic scale. According to his/her preferences, panel were asked to sort the fruit sample on 9-point hedonic scale $(1=$ dislike extremely, 5 = neither like nor dislike, 9 = like very much), taking into account flavor/taste, appearance and texture. Each panel evaluated three samples of each cultivar at each maturity stage, previously randomized to avoid position bias.

\subsection{Sugars and Organic Acids Extraction}

Fresh samples of strawberry, sweet cherry and mulberry fruit $(10 \mathrm{~g})$ were homogenized with $20 \mathrm{~mL}$ of distilled water using a commercial blender (Ika-Labortechnik).The fruit puree was clarified by 
centrifugation at $3000 \mathrm{~g}$ for $10 \mathrm{~min}$. The supernatant was filtered through $0.25-\mu \mathrm{m}$ Millipore filters. Samples were prepared in triplicate, stored in a refrigerator and analyzed within $12 \mathrm{~h}$ of preparation.

\subsection{HPLC Condition Used for Sugar Analysis}

Chromatographic analysis of sugars was carried out on an Agilent 1100-series HPLC system equipped with a quaternary pump (G1311A), vacuum degasser (G1379A), auto-sampler/auto-injector (G1313A ALS), column compartment (G1316A Colcom) and a refractive index detector (model RID10A). The sugars (glucose, fructose and sucrose) were separated on a Bio-Rad Aminex HPX-87K $300 \times 7.8 \mathrm{~mm}$ column (Cat. \#1250142). A Bio-Rad Guard column containing the same stationary phase as the separation column was fitted to the front of the separation column. The mobile phase was ultra pure $\mathrm{H}_{2} \mathrm{O}$ at a flow rate of $0.6 \mathrm{~mL} / \mathrm{min}$. The sample volume injected was $20-\mu \mathrm{L}$. A refractive index detector maintained at $68{ }^{\circ} \mathrm{C}$ was used for detection purposes. The sugars were identified on the basis of comparison of their retention times with those of pure standards (Sigma-Aldrich) and quantified using standard calibration curves (in the range of $1 \mathrm{mg} / 100 \mathrm{~mL}$ to $5 \mathrm{mg} / 100 \mathrm{~mL}$ ). Agilent Chem Station software was used to process the chromatographic data.

\subsection{Sweetness Index}

A sweetness index was used to estimate the total sweetness perception described by Baldwin et al. [35] and Obando-Ulloa et al. [36] as sucrose equivalents (Suceq) according to the formula:

$$
\text { Suceq }=1 \times[\text { Sucrose }]+0.74 \times[\text { Glucose }]+1.73 \times[\text { Fructose }]
$$

\subsection{Condition Used for Organic Acid Analysis}

HPLC analysis of organic acids was performed on an Agilent 1100- series HPLC system equipped with a Quaternary pump (G1311A), vacuum degasser (G1379A), auto-sampler/auto-injector (G1313A ALS), column compartment (G1316A Colcom) and diode array detector (DAD) (model G1315B DAD). The separation was carried out using a Hibar ${ }^{\circledR}$ RP-C18 column $(250 \mathrm{~mm} \times 4.6 \mathrm{~mm} ; 5 \mu$ particle size) from Merck Company (Merck KGaA, 64271 Darmstadt, Germany) thermostated at $30{ }^{\circ} \mathrm{C}$. The mobile phase consisted of 5\% methanol in $25 \mathrm{mM}$ potassium dihydrogen phosphate ( $\mathrm{pH}$ was adjusted to 2.10 by dilute phosphoric acid), and was delivered at a flow rate of $1.0 \mathrm{~mL} / \mathrm{min}$. The mobile phase was filtered through Nylon membrane filter $(47 \mathrm{~mm}, 0.45 \mathrm{~mm})$ and degassed by sonication before use. Target compounds were detected at $215 \mathrm{~nm}$. Quantitative measurements were based on the external standard calibration method. Dilutions 1:0, 1:1, 1:2 and 1:4 of an aqueous solution containing $1 \mathrm{~g} / \mathrm{L}$ of each of the organic acid standards (malic, citric, tartaric and ascorbic acids) were used to prepare the standard curve (peak area versus concentration in $\mathrm{mg} / \mathrm{L}$ ). Calibration curves had correlation coefficients of 0.99 or greater. An Agilent Chem Station was used to process chromatographic data.

\subsection{Statistical Analysis}

Univariate analysis of variance (ANOVA) was performed in each individual fruit trait (sugar or organic acid) using Minitab 2000 Version 13.2 statistical software [37]. The stage of maturity was the factor and a probability value of $p<0.05$ was considered to denote a statistically significant difference. 


\section{Conclusions}

This study is likely to represent the first data on the sugars and non-volatile organic acids of Pakistani strawberry, sweet cherry and mulberry fruits at different maturity stages. Generally, the composition of sugars and organic acids increased as fruit maturity progressed. As far as the nutritional ranking of the tested fruits at fully-ripened stage is concerned, Morus species, especially, M. macroura and $M$. alba were found to be the major source of natural sugars, while strawberry cultivars and black mulberry ( $M$. nigra and M. laevigata) were established to be the most potential source of valuable organic acids. With regard to the composition of sugars and organic acids, the tested Pakistani small fruits have compatible and in some cases superior nutritional value when compared with the same fruits from other locations of the world. It can be suggested that these local fruits can be used widely to meet the nutritional demand of the local communities as well as exported to generate revenue.

\section{Acknowledgements}

The manuscript presented is a part of Ph.D thesis research work of Tahir Mahmood. The authors are grateful to M. Asharf, Department of Botany, University of Agriculture Faisalabad, Pakistan for his technical assistance during revision of this manuscript.

\section{References}

1. Rechkemmer, G. Functional foods-nutrition of the future de-marketing strategy. Res. Report Special Issue 2001, 1, 12-15.

2. Abeles, F.B.; Takeda, F. Cellulase activity and ethylene in ripening strawberry and apple fruits. Sci. Hortic. 1990, 42, 269-275.

3. Aaby, K.; Wrolstad, R.E.; Ekeberg, D.; Skrede, G. Polyphenol composition and antioxidant activity in strawberry purees; impact of achene level and storage. J. Agric. Food Chem. 2007, 55, 5156-5166.

4. Corral-Aguayo, R.D.; Yahia, E.N.; Carrillo-Lopez, A.; Gonzalez-Aguilar, G. Correlation between some nutritional components and the total antioxidant capacity measured with six different assays in eight horticultural crops. J. Agric. Food Chem. 2008, 56, 10498-10504.

5. Basson, C.E.; Groenewald, J.H.; Kossmann, J.; Cronje, C.; Bauer, R. Sugar and acid-related quality attributes and enzyme activities in strawberry fruits: Invertase is the main sucrose hydrolysing enzyme. Food Chem. 2010, 121, 1156-1162.

6. Crespo, P.; Bordonaba, J.G.; Terry, L.A.; Carlen, C. Characterization of major taste and health-related compounds of four strawberry genotypes grown at different Swiss production sites. Food Chem. 2010, 122, 16-24.

7. Montero, M.T.; Molla, E.M.; Esteban, R.M.; Lopez-Andreu, F.J. Quality attributes of strawberry during ripening. Sci. Hortic.1996, 65, 239-250.

8. Terry, L.A.; Chope, G.A.; Gine-Bordonaba, J. Effect of water deficit irrigation and inoculation with Botrytis cinerea on strawberry (Fragaria $x$ ananassa) fruit quality. J. Agric. Food Chem. 2007, 55, 10812-10819. 
9. Bordonaba, J.G.; Terry, L.A. Manipulating the taste-related composition of strawberry fruits $($ Fragaria $\times$ ananassa) from different cultivars using deficit irrigation. Food Chem. 2010, 122, 1020-1026.

10. Serradilla, M.J.; Lozano, M.; Bernalte, M.J.; Ayuso, M.C.; López-Corrales, M.; González-Gómez, D. Physicochemical and bioactive properties evolution during ripening of Ambrunés' sweet cherry cultivar. LWT Food Sci. Technol. 2011, 44, 199-205.

11. Azodanlou, R.; Darbellay, C.; Luisier, J.L.; Villettaz, J.C.; Amadò, R. Development of a model for quality assessment of tomatoes and apricots. Lebensm. Wiss. Technol. 2003, 36, 223-233.

12. Serrano, M.; Guillen, F.; Martinez-Romero, D.; Castillo, S.; Valero, D. Chemical constituents and antioxidant activity of sweet cherry at different ripening stages. J. Agric. Food Chem. 2005, 53, 2741-2745.

13 Pelayo-Zaldivar C.; Ebeler, S.; Kader, A. Cultivar and harvest date effects on flavor and other quality attributes of California strawberries. J. Food Qual. 2005, 28, 78-97.

14 Keutgen, A.J.; Pawelzik, E. Quality and nutritional value of strawberry fruit under long term salt stress. J. Agric. Food Chem. 2008, 107, 1413-1420.

15 Usenik, V.; Fabcic, J.; Stampar, F. Sugars, organic acids, phenolic composition and antioxidant activity of sweet cherry (Prunus avium L.). Food Chem. 2008, 107, 185-192.

16 Kafkas, E.; Kosar, M.; Paydas, S.; Kafkas, S.; Baser, K.H.C. Quality characteristics of strawberry genotypes at different maturation stages. Food Chem. 2007, 100, 1229-1236.

17 Tomoyuki, O.; Kobayashi, M.; Nakamura, T.; Okuyama, A.; Masuda, M., Shiratsuchi, H.; Suda, I. Changes in radical-scavenging activity and components of mulberry fruit during maturation. J. Food Sci. 2006, 71, 18-22.

18 Ozgen, M.; Serce, S.; Kaya, C. Phytochemical and antioxidant properties of anthocyanin-rich Morus nigra and Morus rubra fruits. Sci. Hortic. 2009, 119, 275-279.

19 Ercisli, S.; Orhan, E. Some physico-chemical characteristics of black mulberry (Morus nigra L.) genotypes from Northeast Anatolia region of Turkey. Sci. Hortic. 2008, 116, 41-46.

20 Koyuncu, F. Organic acid composition of native black mulberry fruit. Chem. Nat. Compd. 2004, 40, 367-369.

21 Díaz-Mula, H.M.; Castillo, S.; Martínez-Romero, D.; Valero, D.; Zapata, P.J.; Guillén, F.; Serrano, M. Organoleptic, nutritive and functional properties of sweet cherry as affected by cultivar and ripening stage. Food Sci. Technol. Int. 2009, 15, 535-544.

22 Chang, J.C.; Chang, M.W. "Elongated Fruit No. 1" Mulberry: An elite cultivar for fresh consumption. J. Am. Pomol. Soc. 2010, 64, 101-105.

23 Chitarra, M.I.F.; Chitarra, A.B. Post-Harvest Fruits and Vegetables: Physiology and Handling, 2nd ed.; UFLA: Lavras, Brazil, 2005; p. 785.

24 Castro, I.; Goncalves, O.; Teixeira, J.A.; Vicente, A.A. Comparative study of selva and camarosa strawberries for the commercial market. J. Food Sci. 2002, 67, 2132-2137.

25 Sturm, K.; Koron, D.; Stampar, F. The composition of fruit of different strawberries varieties depending on maturity stage. Food Chem. 2003, 83, 417-422.

26 Ahmad, I.; Sadozai, M.A. Mulberry Production. Bulletin No.12. Research and Development. NTFP Directorate, Khyber Pakhtunkhwa Forest Deptt: Peshawar, Pakistan, 2003; pp. 50-54. 
27 Elmac1, Y.; Altug, T. Flavour evaluation of three black mulberry (Morus nigra) cultivars using GC/MS, chemical and sensory data. J. Sci. Food Agric. 2002, 82, 632-635.

28 Kalt, W.; Prange, R.K.; Lidster, P.D. Postharvest color development of strawberries: Influence of maturity, temperature and light. Can. J. Plant Sci. 1993, 73, 541-548.

29 Dolenc, K.; Stampar, F. An Investigation of the Application and Conditions of Analyses of HPLC Methods for Determining Sugars and Organic Acids in Fruits. Research reports of Biotechnical Faculty, University of Ljubljana: Ljubljana, Slovenia, 1997; Volume 69, pp. 99-106.

30 Koyuncu, M.A.; Dilmaçünal, T. Determination of vitamin C and organic acid changes in strawberry by HPLC during cold storage. Not. Bot. Hort. Agrobot. Cluj. 2010, 38, 95-98.

31 Holcroft, D.M.; Kader, A.A. Controlled atmosphere-induced changes in $\mathrm{pH}$ and organic acid metabolism may affect color of stored strawberry fruit. Postharvest Biol. Technol. 1999, 17, $19-32$.

32 Spayd, S.E.; Morris, J.R. Effects of immature fruit and holding on strawberry puree and color stability. J. Amer. Soc. Hort. Sci. 1981, 106, 211-216.

33 Cordenunsi, B.R.; Nascimento, J.R.O.; Genovese, M.I.; Lajolo, F.M. Influence of cultivar on quality parameters and chemical composition of strawberry fruits grown in Brazil. J. Agric. Food Chem. 2002, 50, 2581-2586.

34 Souci, S.W.; Fachmann, W.; Kraut, H. Food Composition and Nutritional Tables; Wissensch Verlagsgesellsch: Stuttgart, Germany, 1986.

35 Baldwin, E.A.; Scott, J.W.; Einstein, M.A.; Malundo, T.M.M.; Carr, B.T.; Shewfelt, R.L.; Tandon, K.S. Relationship between sensory and instrumental analysis for tomato flavor. J. Am. Soc. Hort. Sci. 1998, 123, 906-915.

36 Obando-Ulloa, J.M.; Eduardo, I.; Monforte, A.J.; Fernández-Trujillo, J.P. Identification of QTLs related to sugar and organic acid composition in melon using near-isogenic lines. Sci. Hortic. 2009, 121, 425-433.

37 Minitab, version 13.2; Statistical Software; Minitab, Inc.: State College, PA, USA, 2000.

(C) 2012 by the authors; licensee MDPI, Basel, Switzerland. This article is an open access article distributed under the terms and conditions of the Creative Commons Attribution license (http://creativecommons.org/licenses/by/3.0/). 